\title{
New Predictive Equation for Optimal Continuous Positive Airway Pressure in Adult Patients with Obstructive Sleep Apnea
}

\author{
Kanokkan Pengsakul, B.Sc. ${ }^{1}$, Krongthong Tawaranurak, M.D. ${ }^{2}$, Chuanchom Bumrungsena, B.N.S. ${ }^{3}$, \\ Chitladda Chaimongkol, B.N.S. ${ }^{3}$, Jarurin Pitanupong, M.D. ${ }^{4}$
}

\begin{abstract}
${ }^{1}$ Songklanagarind Sleep Center, Faculty of Medicine, Prince of Songkla University, Hat Yai, Songkhla 90110, Thailand. ${ }^{2}$ Department of Otolaryngology, Head and Neck Surgery, Faculty of Medicine, Prince of Songkla University, Hat Yai, Songkhla 90110, Thailand.

${ }^{3}$ Nursing Department, Faculty of Medicine, Prince of Songkla University, Hat Yai, Songkhla 90110, Thailand.

${ }^{4}$ Department of Psychiatry, Faculty of Medicine, Prince of Songkla University, Hat Yai, Songkhla 90110, Thailand.

Received 1 May 2021 • Revised 21 June 2021 • Accepted 22 June 2021 • Published online 1 September 2021
\end{abstract}

\begin{abstract}
:
Objective: This study aimed to develop and validate a new continuous positive airway pressure (CPAP) prediction equation and compare it with other formulas.

Material and Methods: We retrospectively included patients with obstructive sleep apnea who underwent a CPAP titration study between January 2012 and December 2016. All clinical and polysomnographic data were collected. The new prediction equation was developed using the first data set, and the predictability performance was validated using the second data set.

Results: Among the 266 enrolled patients, 73.7\% were male, and the mean body mass index (BMI) was $30.8 \pm 7.4$ $\mathrm{kg} / \mathrm{m}^{2}$. Five variables, namely age, BMI, neck circumference (NC), apnea-hypopnea index (AHI), and minimum pulse oxygen saturation ( $\mathrm{Min} \mathrm{SpO}_{2}$ ), highly correlated with the optimal titration pressure, and were therefore included in the equation, as stated below:

Predicted pressure $\left(\mathrm{cm} \mathrm{H}_{2} \mathrm{O}\right)=2.26+(0.02 \times \mathrm{Age})+(0.04 \times \mathrm{BMI})+(0.11 \times \mathrm{NC})+(0.04 \times \mathrm{AHI})-\left(0.04 \times \mathrm{Min} \mathrm{SpO}_{2}\right)$
\end{abstract}

Contact: Krongthong Tawaranurak, M.D.

Department of Otolaryngology, Head and Neck Surgery,

Faculty of Medicine, Prince of Songkla University, Hat Yai, Songkhla 90110, Thailand.

E-mail: golf_psu@hotmail.com

Jing reserved.

This is an open access article under the CC BY-NC-ND license

(http://www.jhsmr.org/index.php/jhsmr/about/editorialPolicies\#openAccessPolicy).

J Health Sci Med Res 2022;40(3):271-279 doi: 10.31584/jhsmr.2021834 www.jhsmr.org 
This equation accounted for $54.4 \%$ of the variance in predicting the optimal titration pressure $\left(R^{2}=0.544, p-v a l u e<0.001\right)$. Its optimal estimation was $62.0 \%$ in the validated group. The equation-derived predicted pressure correlated with good agreement with the laboratory-derived optimal titration pressure $(r=0.70,95 \% \mathrm{Cl}=0.6335-0.755, p-v a l u e<0.001)$ according to Bland-Altman analysis.

Conclusion: Our equation is highly consistent with the CPAP titration study in predicting fixed CPAP pressure, and is thereby beneficial for sleep technicians in establishing a starting pressure for such studies at a sleep laboratory.

Keywords: continuous positive airway pressure, obstructive sleep apnea, optimal pressure, predictive equation, sleep apnea

\section{Introduction}

Obstructive sleep apnea (OSA) is a common sleep problem with estimated prevalences among adults from 30 to 70 years of age; approximately $14.0 \%$ of men and $5.0 \%$ of women have an apnea-hypopnea index (AHI) of more than 5 events/hour with symptoms of daytime sleepiness. ${ }^{1}$ OSA not only affects sleep quality but also causes cardiovascular morbidity and mortality. ${ }^{2,3}$ The primary treatment for moderate to severe OSA is continuous positive airway pressure (CPAP), which provides pneumatic splinting of the collapsed upper airway. It effectively reduces $\mathrm{AHI}$, improves sleepiness and quality of life, and may prevent cardiovascular complications. ${ }^{4}$ The laboratory-conducted full-night CPAP titration study is still generally preferred to determine the minimum pressure required to prevent the patient's respiratory events. ${ }^{5}$ This procedure requires at least two overnight sleep studies, and is therefore time consuming, and the split-night CPAP titration study, which includes initial diagnostic polysomnography (PSG) followed by a manual CPAP titration study on the same night is an alternative choice. However, this technique also requires time-consuming titration and often fails to obtain the optimal titration pressure $(\mathrm{P}$-titrated). Practical issues related to the limitations of laboratory CPAP titration are widely solved by unattended automatic positive airway pressure (APAP) titration with using $90^{\text {th }}$ or $95^{\text {th }}$ percentile of CPAP pressure.
According to some guidelines, only certain APAP devices can be used in determining the treatment pressure for patients without significant comorbidities suffering from OSA. ${ }^{6}$ The issue of predicting effective CPAP levels has also been studied. In addition, various predictive formulas for optimal pressure are based on differences in clinical variables or PSG parameters. ${ }^{7-13}$ In this study, we aimed to develop and validate a new CPAP prediction equation to help establish the starting pressure for CPAP titration study at a sleep laboratory and to compare it with other formulas in estimating the CPAP.

\section{Material and Methods}

This retrospective study included patients with OSA who were at least 20 years old and had undergone a CPAP titration study at the Sleep Laboratory Center of Songklanagarind Hospital, a university hospital in Southern Thailand, between January 2012 and December 2016. All enrolled subjects had to have obtained the optimal P-titrated level before admission to the study. We collected all clinical and PSG data for each patient including age, gender, Epworth Sleepiness Scale (ESS) ${ }^{14,15}$, body mass index (BMI), neck circumference (NC), Friedman tongue position (FTP), AHI, minimal pulse oxygen saturation (Min $\mathrm{SpO}_{2}$ ), oxygen desaturation index (ODI), and optimal P-titrated. The NC was measured at the Adam's apple level, and 
the FTP was assessed in the upright position with the mouth open without tongue protrusion. ${ }^{16,17}$ The ODI was the average number of desaturation episodes per hour of recording in which the oxygen saturation decreased by $3.0 \%$. Patients with incomplete data were excluded from the study.

\section{PSG and CPAP titration studies}

Type 1 PSG (Compumedics E series, Compumedics, Abbotsford, Australia), which consisted of electroencephalometry, electro-oculography, chin and leg electromyography, electrocardiography, thermistors and a nasal pressure transducer for oronasal airflow, thoracic and abdominal belts for respiratory efforts, pulse oximetry for oxyhemoglobin concentration, a tracheal microphone for snoring, and sensors for assessing sleeping position, was conducted for each patient. Data from the recordings of each parameter were scored manually using standard criteria. ${ }^{18}$ An apnea event was scored when the thermistor signal decreased by $\geq 90.0 \%$ of the pre-event baseline for $\geq 10$ seconds. We scored hypopnea when the nasal pressure signals decreased by $30.0 \%$ for $\geq 10$ seconds associated with $\geq 3.0 \%$ oxygen desaturation or an arousal. The $\mathrm{AHI}$ was calculated by the number of apnea and hypopnea events per hour of total sleep time. ${ }^{19}$ In cases in which the $\mathrm{AHI}$ was at least 40 during a minimum of 2 hours of diagnostic PSG, split-night studies were performed. Certified sleep technicians in the sleep laboratory manually performed the CPAP titration studies. The pressure was started at $4 \mathrm{~cm}$ $\mathrm{H}_{2} \mathrm{O}$ and then increased by at least $1 \mathrm{~cm} \mathrm{H} \mathrm{H}_{2}$ at an interval of $\geq 5$ minutes. If 2 obstructive apneas, 3 hypopneas, or 5 respiratory-effort-related arousals, or at least 3 min of loud or unambiguous snoring occurred, the CPAP was increased. The optimal P-titrated was defined as the lowest effective pressure that reduced $\mathrm{AHI}<5$ for at least 15 minutes, a minimum $\mathrm{SpO}_{2}$ level above $90.0 \%$ at the selected pressure, and included supine rapid eye movement (REM) sleep at the selected pressure that was not continually interrupted by spontaneous arousals or awakenings. ${ }^{20}$

All baseline data are presented as means (standard deviation (S.D.)) for continuous variables, numbers (\%) for categorical variables, or medians (interquartile range (IQR)) for original variables. In comparing between groups, we used chi-square or Fisher's exact test for nominal variables and Mann-Whitney $U$ test for original variables. Two data sets, the prediction equation development and validation phases, were the source of the independent data.

In developing an equation that could predict the optimal pressure, all variables from the first data set with p-value $<0.050$ on univariate analysis were used to identify the independent predictive variables through stepwise multiple linear regression analysis. The relationships between the baseline data (e.g., anthropometric and PSG variables) and the optimal $\mathrm{P}$-titrated derived from the titration studies were explored using Pearson correlation coefficients. For the validation phase, we used all variables from the second data set to assess the mean differences between the optimal P-titrated and predicted pressures (P-predicted) from our prediction equation using a Bland-Altman plot, and to compare this equation with the formulas of Hoffstein, Lin, Luo, Lee, and $\mathrm{Wu}^{7-12}$ The prediction performances were classified into optimal estimation (difference between P-titrated and P-predicted) of $\left.\leq 1 \mathrm{~cm} \mathrm{H}_{2} \mathrm{O}\right),>1 \mathrm{~cm} \mathrm{H}_{2} \mathrm{O}$ increment, or $>1 \mathrm{~cm} \mathrm{H} \mathrm{H}_{2}$ decrement. These estimations would determine how well P-predicted approximated P-titrated in individual subjects. Normality was checked by the Shapiro-Wilk test, and the mean pressure differences were analyzed by the Student's t-test or Wilcoxon rank sum test. All statistical analyses were performed using Epidata software (version 3.1) and $R$ (version 3.5.1). A p-value< 0.050 was considered to be statistically significant. 


\section{Results}

Most of the enrolled subjects were males with obesity who suffered from severe OSA with significant oxygen desaturation and daytime sleepiness. Age, BMI, NC, AHI, and $\mathrm{Min} \mathrm{SpO}_{2}$ of both data sets demonstrated no statistically significant differences (Table 1).

\section{Prediction equation development}

Of the 266 enrolled patients, $73.7 \%$ were male. The mean BMI was $30.8 \pm 7.4 \mathrm{~kg} / \mathrm{m}^{2}$, while the mean $\mathrm{NC}$ was $39.4 \pm 3.8 \mathrm{~cm}$. The mean ESS score was $10.0 \pm 4.4$, and a majority of the patients had FTP class 3-4 (80.4\%). The mean $\mathrm{AHI}$ was $51.1 \pm 29.5$ events/hour with a minimum oxygen saturation of $78.6 \% \pm 8.7 \%$. The mean P-titrated

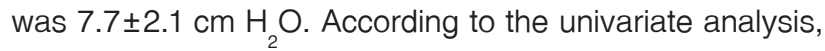

age, $\mathrm{BMI}, \mathrm{NC}, \mathrm{AHI}, \mathrm{Min} \mathrm{SpO}_{2}$, and $\mathrm{ODI}$ were significantly correlated with optimal P-titrated, and they were considered in the multiple linear regression analysis (Table 2 ). In the multiple linear regression analysis, only five variables, namely age, BMI, $\mathrm{NC}, \mathrm{AHI}$, and $\mathrm{Min} \mathrm{SpO}_{2}$, had a high correlation with optimal P-titrated, and were therefore included in the equation (Table 3 ). This equation accounted for $54.4 \%$ of the variance in optimal P-titrated $\left(R^{2}=0.544\right.$, adjusted $R^{2}=0.535, p$-value $\left.<0.001\right)$. The prediction equation was then created as follows:

$$
\text { P-predicted }\left(\mathrm{cm} \mathrm{H}_{2} \mathrm{O}\right)=2.26+(0.02 \times \mathrm{Age})+(0.04 \mathrm{x}
$$
$\mathrm{BMI})+(0.11 \times \mathrm{NC})+(0.04 \times \mathrm{AHI})-\left(0.04 \times \mathrm{Min} \mathrm{SpO}_{2}\right)$ where $\mathrm{BMl}=$ body mass index, $\mathrm{NC}=$ neck circum-ference,

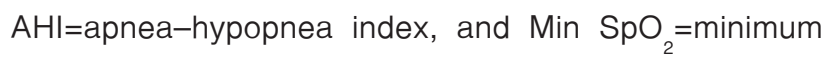
pulse oxygen saturation.

Table 1 Baseline characteristics and polysomnographic data of study patients

\begin{tabular}{llll}
\hline Variable & $\begin{array}{l}\text { Prediction equation } \\
\text { development set } \\
(\mathbf{n = 2 6 6 )}\end{array}$ & $\begin{array}{l}\text { Validation set } \\
(\mathbf{n = 2 7 4})\end{array}$ & $\mathbf{p}$-value \\
\hline Age (years), mean (S.D.) & $49.6(13.0)$ & $48.6(14.1)$ & 0.369 \\
BMI (kg/m²), mean (S.D.) & $30.8(7.4)$ & $31.2(7.4)$ & 0.580 \\
NC (cm), mean (S.D.) & $39.5(3.8)$ & $39.8(4.1)$ & 0.313 \\
ESS scores, median (S.D.) & $10.0(7.0,12.0)$ & $9.0(6.0,12.0)$ & 0.032 \\
AHI (eventshour), mean (S.D.) & $51.1(29.5)$ & $49.4(27.0)$ & 0.494 \\
Min SpO (\%), mean (S.D.) & $78.6(8.7)$ & $77.2(11.1)$ & 0.095 \\
ODI (eventshour), mean (S.D.) & $41.4(29.0)$ & $35.6(28.1)$ & 0.018 \\
FTP scale, number (\%) & & & 0.044 \\
$\quad 1-2$ & $26(19.5)$ & $29(21.8)$ & \\
$\quad$ 3-4 & $107(80.4)$ & $104(78.2)$ & $7.4(1.8)$ \\
Optimal titration pressure (cm H O), mean (S.D.) & $7.7(2.1)$ & 0.048 \\
\hline
\end{tabular}

$\mathrm{BMI}=$ body mass index, $\mathrm{NC}=$ neck circumference, ESS=Epworth Sleepiness Scale, AHI=apnea-hypopnea index, Min $\mathrm{SpO}_{2}=$ minimum pulse oxygen saturation, $\mathrm{ODI}=$ oxygen desaturation index, $\mathrm{FTP}=$ Friedman tongue position, $\mathrm{kg} / \mathrm{m}^{2}=$ kilograms per square meter, $\mathrm{cm} \mathrm{H}_{2} \mathrm{O}=$ centimeters water, $\mathrm{SD}=$ standard deviation, $\mathrm{IQR}=$ interquartile range 
Table 2 Relationship of variables and optimal titration pressure by univariate analysis $(n=266)$

\begin{tabular}{llll}
\hline Variable & Coefficient $(\mathrm{SE})$ & $\mathbf{R}^{2}$ & $\mathbf{p}$-value \\
\hline $\mathrm{Age}$ & $-0.010(0.010)$ & 0.004 & $<0.001$ \\
$\mathrm{BMI}$ & $0.108(0.016)$ & 0.140 & $<0.001$ \\
$\mathrm{NC}$ & $0.272(0.030)$ & 0.238 & $<0.001$ \\
$\mathrm{AHI}$ & $0.048(0.003)$ & 0.443 & $<0.001$ \\
$\mathrm{Min} \mathrm{SpO}$ & $-0.104(0.014)$ & 0.182 & $<0.001$ \\
$\mathrm{ODI}_{2}$ & $0.049(0.003)$ & 0.444 & $<0.001$ \\
\hline
\end{tabular}

$\mathrm{BMI}=$ body mass index, $\mathrm{NC}=$ neck circumference, $\mathrm{AHI}=$ apneahypopnea index, Min $\mathrm{SpO}_{2}=$ minimum pulse oxygen saturation, $\mathrm{ODI}=$ oxygen desaturation index, $\mathrm{SE}=$ standard error

Table 3 Multiple linear regression analysis to predict the optimal titration pressure $(n=266)$

\begin{tabular}{llll}
\hline Variable & Coefficient & SE & p-value \\
\hline Age & 0.024 & 0.007 & 0.001 \\
$\mathrm{BMl}$ & 0.036 & 0.015 & 0.018 \\
$\mathrm{NC}$ & 0.112 & 0.030 & $<0.001$ \\
$\mathrm{AHI}$ & 0.037 & 0.003 & $<0.001$ \\
$\mathrm{Min} \mathrm{SpO}$ & -0.041 & 0.011 & $<0.001$ \\
\hline
\end{tabular}

$\mathrm{BMI}=$ body mass index, $\mathrm{NC}=$ neck circumference, $\mathrm{AHI}=$ apneahypopnea index, $\mathrm{Min} \mathrm{SpO}_{2}=$ minimum pulse oxygen saturation, $\mathrm{SE}=$ standard error

\section{Validation of prediction equation}

After developing the equation, we validated it by using the second data set of the subjects $(N=274)$. The mean $\mathrm{BMl}$ and $\mathrm{NC}$ were $31.2 \pm 7.4 \mathrm{~kg} / \mathrm{m}^{2}$ and $39.8 \pm 4.1$ $\mathrm{cm}$, respectively. The mean $\mathrm{AHI}$ was $49.4 \pm 27.0$ events/ hour, with the mean $\mathrm{Min} \mathrm{SpO}_{2}$ of $77.2 \% \pm 11.1 \%$. The mean P-titrated of the second data set was $7.4 \pm 1.8 \mathrm{~cm} \mathrm{H}_{2} \mathrm{O}$, while that from our equation was $7.7 \pm 1.6 \mathrm{~cm} \mathrm{H}_{2} \mathrm{O}$. The correlation coefficients between the laboratory-derived pressure and the equation-derived pressure were $r=$ 0.6995, 95\% Cl=0.6335-0.755, and p-value $<0.001$. In addition, Bland-Altman analysis showed good agreement between the two methods with a mean difference of -0.4 $\pm 1.3 \mathrm{~cm} \mathrm{H} \mathrm{O}_{2}$ (95\% limits of agreement -2.95 to $2.15 \mathrm{~cm}$ $\left.\mathrm{H}_{2} \mathrm{O}\right)$. Only 13 of the 274 patients $(4.7 \%)$ were outside the limits of agreement.

\section{Comparison between our equation and other} formulas

The optimal estimation of our equation was $62.0 \%$ (170 in 274), whereas that of the Hoffstein's formula was $45.6 \%$, and the optimal estimations of Lin, Luo, Lee, and Wu's formulas, which were acquired from Asian studies,

Table 4 Predictive performance of our prediction equation in comparison with that of five previously reported formulas $(n=274)$

\begin{tabular}{|c|c|c|c|c|c|}
\hline \multirow{2}{*}{ Prediction formula } & \multirow{2}{*}{$\begin{array}{l}\text { Mean P-predicted } \\
\text { (S.D.), } \mathrm{cm} \mathrm{H}_{2} \mathrm{O}\end{array}$} & \multirow{2}{*}{$\begin{array}{l}\text { Mean difference } \\
\text { between P-titrated } \\
\text { and P-predicted } \\
\text { (S.D.) }\end{array}$} & \multicolumn{3}{|c|}{$\begin{array}{l}\text { Difference between P-titrated and P-predicted } \\
\text { Number }(\%)\end{array}$} \\
\hline & & & $\pm 1 \mathrm{~cm} \mathrm{H}_{2} \mathrm{O}$ & $\begin{array}{l}>1 \mathrm{~cm} \mathrm{H}_{2} \mathrm{O} \\
\text { decrement }\end{array}$ & $\begin{array}{l}>1 \mathrm{~cm} \mathrm{H}_{2} \mathrm{O} \\
\text { increment }\end{array}$ \\
\hline Our prediction equation & $7.7(1.6)$ & $-0.4(1.3)$ & $170(62.0)$ & $75(27.4)$ & $29(10.6)$ \\
\hline Hoffstein et al. & $7.3(2.1)$ & $0.1(1.7)$ & $125(45.6)$ & $67(24.5)$ & $82(29.9)$ \\
\hline Lin et al. & $8.0(2.0)$ & $-0.6(1.7)$ & $135(49.3)$ & $106(38.7)$ & $33(12.0)$ \\
\hline Luo et al. & $8.1(2.2)$ & $-0.7(1.8)$ & $132(48.2)$ & $108(39.4)$ & $34(12.4)$ \\
\hline Lee et al. & $8.9(2.3)$ & $-1.6(1.7)$ & $85(31.0)$ & $170(62.0)$ & $19(6.9)$ \\
\hline Wu et al. & $8.1(2.2)$ & $-0.7(1.7)$ & $138(50.4)$ & $104(38.0)$ & $32(11.7)$ \\
\hline
\end{tabular}

P-titrated=optimal titration pressure, $\mathrm{P}$-predicted=predicted pressure, $\mathrm{cm} \mathrm{H}_{2} \mathrm{O}=$ centimeters water, S.D.=standard deviation 
were $49.3 \%, 48.2 \%, 31.0 \%$, and $50.4 \%$, respectively. However, Lee's formula clearly showed a pressure difference of $>1 \mathrm{~cm} \mathrm{H} O$ decrement, which was up to $62.0 \%$ (Table 4).

\section{Discussion}

The present study examined a large group of patients with OSA who underwent CPAP titration studies, which data were used to develop a new equation for predicting CPAP for Asian patients, which was then compared with five previously reported formulas in a separate validation group. The Hoffstein formula was the first widely used equation for predicting CPAP in Caucasian populations.
The four remaining formulas were based on studies in Asian populations, using different parameters. Regarding our equation, CPAP prediction was determined by a combination of age, BMI, NC, AHI, and $\mathrm{Min} \mathrm{SpO}_{2}$. This equation accounted for $54.0 \%$ of the total variance. The $\mathrm{P}$-predicted derived from our equation positively correlated with the optimal P-titrated derived from the sleep laboratory $(r=0.7, p-v a l u e<0.001)$, showing a good agreement between the two pressure-identifying methods. Moreover, the optimal estimation of our formula was $62.0 \%$, whereas that of $\mathrm{Wu}$ formula was only $50.0 \%$. The Lee formula, which only uses the ESS score, tended to show a lower CPAP pressure in our patients $(62.0 \%)$. In contrast, the Hoffstein formula

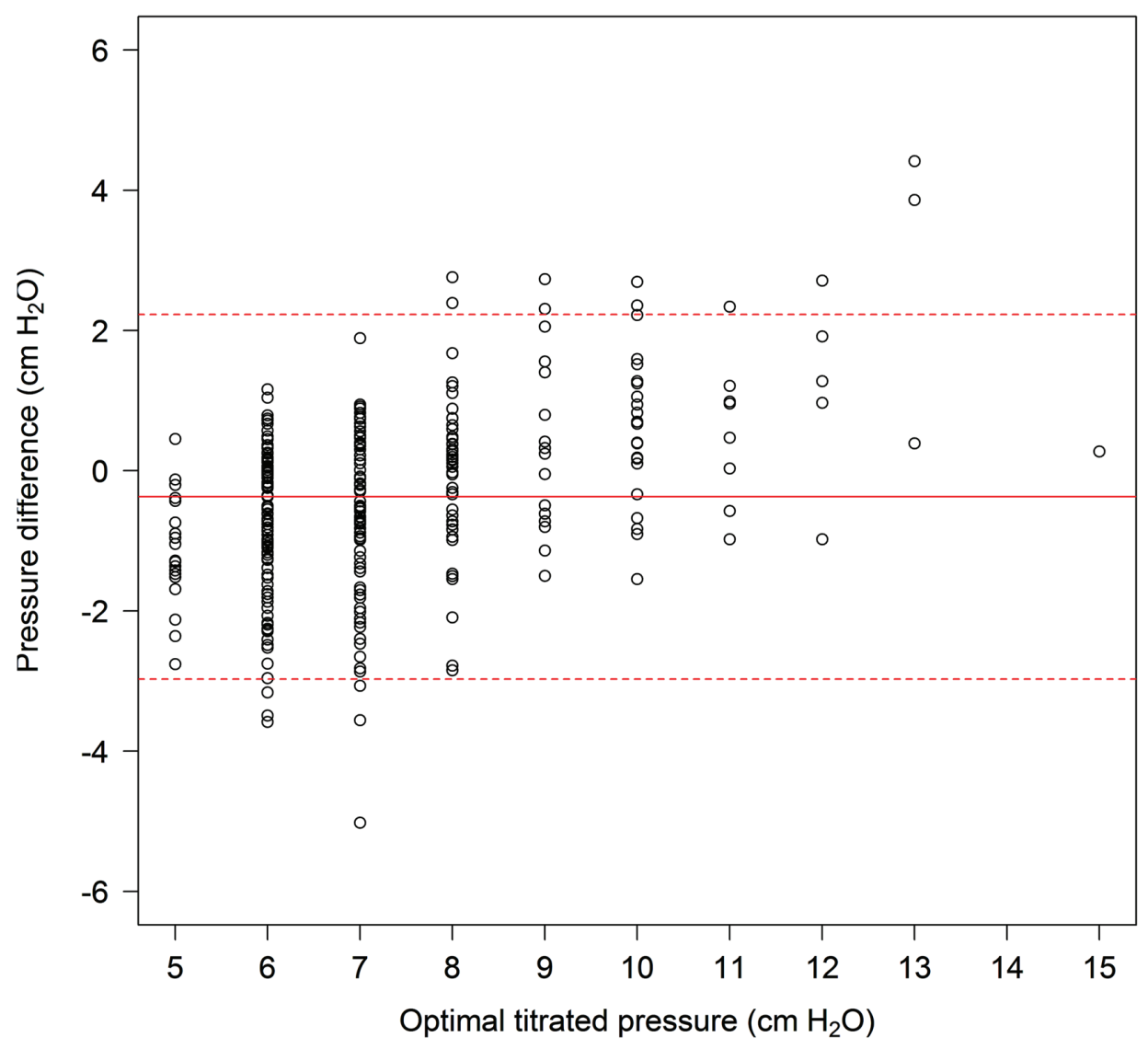

Figure 1 Bland-Altman plot showing the differences against the mean of the optimal titration pressure $(P-t i t r a t e d)$ and predicted pressure (P-predicted). 
tended to show a higher pressure, reaching up to $30.0 \%$, for Asian patients.

According to the multivariate analysis in this study, age was significantly related to the optimal P-titrated. The presence of this variable in our equation differentiates our formula from all other proposed formulas. The variable NC was also related to the optimal P-titrated in our study, consistent with the study of Kirgezen et al., which reported that the NC was one of the major factors affecting the optimal P-titrated of a CPAP device. ${ }^{21}$ The remaining variables such as $\mathrm{BMI}, \mathrm{AHI}$, and $\mathrm{Min}_{\mathrm{SpO}}$ were significantly related to the optimal $\mathrm{P}$-titrated, similar to the majority of the formulas. ${ }^{7-13}$ However, we found that the ESS scores and sex were not significantly associated with the optimal P-titrated.

The effect of race on CPAP prediction should also be considered. Generally, Asian and Caucasian patients have different craniofacial and body structures. In addition, Asian patients are typically less obese and have a smaller neck size than Caucasians, as reported in several previous studies. ${ }^{9-12}$ However, in this study, the Hoffstein formula could predict CPAP at an optimal estimation of only $45.0 \%$, similar to other Asian-derived formulas. This might be due to a slightly higher mean $\mathrm{BMI}$ in the patients with OSA included our study $\left(31.2 \pm 7.4 \mathrm{~kg} / \mathrm{m}^{2}\right)$ similar to the BMI of $34.0 \pm 8.0 \mathrm{~kg} / \mathrm{m}^{2}$ in the Hoffstein study. Surprisingly, the optimal estimation of the Lee formula in predicting pressure was only $31.0 \%$; hence, it mostly tended to predict CPAP pressure at a lower level (62.0\%). Also, the ESS scores are subjective and thus somewhat unreliable with various possible biases.

PSG is an important tool for diagnosing sleep apnea. Unfortunately, the full procedure is quite costly, thus making the diagnostic PSG followed by a second CPAP titration study less accessible for many institutions. One alternative option is to use the split-night PSG procedure, which includes both a diagnostic portion and a
CPAP titration portion, if OSA is found. This approach is both cost effective and convenient for patients. Long-term CPAP use has no difference between this technique and the standard full-night PSG. ${ }^{22,23}$ However, there are still some concerns regarding the split-night study in terms of an inadequate time for proper titration, which should last at least 3 hours. Moreover, PSG during the CPAP titration portion should include respiratory event elimination during both REM and non-rapid eye movement sleep. If the respiratory events are not eliminated, then the CPAP has not obtained optimal titration. Split-night titration studies are more commonly associated with unsuccessful CPAP titration than full-night titration $(50.0 \%$ vs. $35.5 \%) .{ }^{24}$ Our formula provides an optimal estimation of CPAP of as high as $62.0 \%$. Therefore, this formula might improve the manual CPAP titration success by predicting the starting pressure, especially in split-night studies with limited time. In addition, it may be beneficial in some resource-limited settings to help determine the fixed CPAP for adult patients with OSA. Although the PSG titration is still the standard method for obtaining a fixed pressure for CPAP, titration with an automatic CPAP device or predictive formula is being increasingly used in many developed countries. Some previous studies have shown that home CPAP titrations repeated over multiple nights or various predictive equations can determine an appropriate therapeutic prescription for fixed CPAP in most patients. ${ }^{25,26}$ Moreover, recent data have supported that pressures differing by only a few $\mathrm{cm} \mathrm{H}_{2} \mathrm{O}$ from the standard titrated level may be reasonably effective in reducing respiratory events and somnolence. ${ }^{25-30}$ However, an inappropriate CPAP pressure can cause undesirable side effects and affect treatment adherence. Thus, long-term CPAP compliance and clinical consequences should be further studied in patients using this pressure-derived formula.

For the study limitations, this study did not include parameters from clinical anatomical evaluation (FTP, tonsil 
sizes, etc.). Some predicted formulas have proposed a potential benefit from using anatomical evaluation parameters, such as FTP and hyomental distance. However, performing upper-airway anatomical evaluation in all patients is not practical in some multidisciplinary sleep centers. ${ }^{13}$ In addition, this formula was developed and compared with other formulas at only one center. The subjective variables could be interpreted differently between examiners among different sleep centers, which might give rise to different outcomes.

\section{Conclusion}

Our equation is highly consistent with the CPAP titration study in predicting the optimal CPAP pressure. It might help sleep technicians establish a starting pressure for CPAP titration studies at a sleep laboratory. Furthermore, it may be useful in some resource-limited settings to determine the CPAP pressure for adult patients with OSA.

\section{Acknowledgement}

The authors would like to thank Miss Nannapat Pruphetkaew for her assistance in data analysis.

\section{Funding sources}

This work was supported by the Medical Research Council (grant number 60-323-03-7)

\section{Conflict of interest}

None

\section{References}

1. Peppard PE, Young $\mathrm{T}$, Barnet $\mathrm{JH}$, Palta M, Hagen EW, Hla KM. Increased prevalence of sleep-disordered breathing in adults. Am J Epidemiol 2013;177:1006-14.

2. Epstein LJ, Kristo D, Strollo PJ, Friedman N, Malhotra A, Patil SP, et al. Clinical guideline for the evaluation, management and long-term care of obstructive sleep apnea in adults. J Clin Sleep Med 2009;5:263-76.
3. Somers VK, White DP, Amin R, Abraham WT, Costa F, Culebras A, et al. Sleep apnea and cardiovascular disease: an American Heart Association/American College of Cardiology Foundation Scientific Statement from the American Heart Association Council for High Blood Pressure Research Professional Education Committee, Council on Clinical Cardiology, Stroke Council, and Council on Cardiovascular Nursing (2008). J Am Coll Cardiol 2008;52:686-717.

4. Kushida CA, Littner MR, Hirshkowitz M, Morgenthaler TI, Alessi CA, Bailey D, et al. Practice parameters for the use of continuous and bilevel positive airway pressure devices to treat adult patients with sleep-related breathing disorders. Sleep 2006; 29:375-80.

5. Kushida CA, Littner MR, Morgenthaler T, Alessi CA, Bailey D, Coleman J, et al. Practice parameters for the indications for polysomnography and related procedures: an update for 2005. Sleep 2005;28:499-521.

6. Morgenthaler TI, Aurora RN, Brown T, Zak R, Alessi C, Boehlecke $B$, et al. Practice parameters for the use of autotitrating continuous positive airway pressure devices for titrating pressures and treating adult patients with obstructive sleep apnea syndrome: an update for 2007. An American Academy of Sleep Medicine report. Sleep 2008;31:141-7.

7. Miljeteig $\mathrm{H}$, Hoffstein V. Determinants of continuous positive airway pressure level for treatment of obstructive sleep apnea. Am Rev Respir Dis 1993;147:1526-30.

8. Oliver Z, Hoffstein V. Predicting effective continuous positive airway pressure. Chest 2000;117:1061-4.

9. Lin IF, Chuang ML, Liao YF, Chen NH, Li HY. Predicting effective continuous positive airway pressure in Taiwanese patients with obstructive sleep apnea syndrome. J Formos Med Assoc 2003;102:215-21.

10. Luo J, Xiao S, Quu Z, Song N, Luo Y. Comparison of manual versus automatic continuous positive airway pressure titration and the development of a predictive equation for therapeutic continuous positive airway pressure in Chinese patients with obstructive sleep apnoea. Respirology 2013;18:528-33.

11. Lee GH, Kim MJ, Lee EM, Kim CS, Lee SA. Prediction of optimal CPAP pressure and validation of an equation for Asian patients with obstructive sleep apnea. Respir Care 2013;58:810-5.

12. Wu MF, Hsu JY, Huang WC, Shen GH, Wang JM, Wen CY, et al. Should sleep laboratories have their own predictive formulas for continuous positive airway pressure for patients 
with obstructive sleep apnea syndrome? J Chin Med Assoc $2014 ; 77: 283-9$

13. Lai CC, Friedman M, Lin HC, Wang PC, Hwang MS, Hsu CM, et al. Clinical predictors of effective continuous positive airway pressure in patients with obstructive sleep apnea/ hypopnea syndrome. Laryngoscope 2015;125:1983-7.

14. Johns MW. A new method for measuring daytime sleepiness: the Epworth Sleepiness Scale. Sleep 1991;14:540-5.

15. Banhiran W, Assanasen P, Nopmaneejumruslers C, Metheetrairut C. Epworth Sleepiness Scale in obstructive sleep disordered breathing: the reliability and validity of the Thai version. Sleep Breath 2011;15:571-7.

16. Friedman $M$, Ibrahim $H$, Bass L. Clinical staging for sleepdisordered breathing. Otolaryngol Head Neck Surg 2002; $127: 13-21$

17. Friedman M, Salapatas AM, Bonzelaar LB. Updated Friedman staging system for obstructive sleep apnea. Adv Otorhinolaryngol 2017;80:41-8.

18. Berry RB, Brooks R, Gamaldo C, Harding SM, Lloyd RM, Quan SF, et al. AASM scoring manual updates for 2017 (Version 2.4). J Clin Sleep Med 2017;13:665-6

19. Kapur VK, Auckley DH, Chowdhuri S, Kuhlmann DC, Mehra $\mathrm{R}$, Ramar $\mathrm{K}$, et al. Clinical practice guideline for diagnostic testing for adult obstructive sleep apnea: an American Academy of Sleep Medicine clinical practice guideline. J Clin Sleep Med 2017;13:479-504.

20. Kushida CA, Chediak A, Berry RB, Brown LK, Gozal D, Iber C, et al. Positive Airway Pressure Titration Task Force of the American Academy of Sleep Medicine Clinical guidelines for the manual titration of positive airway pressure in patients with obstructive sleep apnea. J Clin Sleep Med 2008;4:157-71.

21. Kırgezen T, Bilici S, Çakır M, Ceyran Ö, Chasan M, Yiğit Ö. Factors affecting optimal titration pressure of continuous positive airway pressure device in patients with obstructive sleep apnea syndrome. Turk Arch Otorhinolaryngol 2020;58: 80-6.
22. McArdle N, Grove A, Devereux G, Mackay-Brown L, Mackay T, Douglas NJ. Split-night versus full-night studies for sleep apnoea/hypopnoea syndrome. Eur Respir J 2000;15:670-5.

23. BaHammam AS, ALAnbay E, Alrajhi N, Olaish AH. The success rate of split-night polysomnography and its impact on continuous positive airway pressure compliance. Ann Thorac Med 2015;10:274-8

24. Farghaly S, Shaaban LH. Efficacy of split night CPAP titration in moderate and severe obstructive sleep apnea syndrome patients. Egypt J Chest Dis Tuberc 2016;65:251-7.

25. Callahan CY, Norman RG, Taxin Z, Mooney AM, Rapoport DM, Ayappa I. Multinight recording and analysis of continuous positive airway pressure airflow in the home for titration and management of sleep disordered breathing. Sleep 2013;36: 535-5F.

26. Marrone O, Salvaggio A, Romano S, Insalaco G. Automatic titration and calculation by predictive equations for the determination of therapeutic continuous positive airway pressure for obstructive sleep apnea. Chest 2008;133:670-6.

27. Farré R, Gozal D, Montserrat JM. Alternative procedure to individual nasal pressure titration for sleep apnea. J Clin Med 2021;10:1453.

28. Masa JF, Jiménez A, Durán J, Capote F, Monasterio C, Mayos $\mathrm{M}$, et al. Alternative methods of titrating continuous positive airway pressure: a large multicenter study. Am J Respir Crit Care Med 2004;170:1218-24.

29. West SD, Jones DR, Stradling JR. Comparison of three ways to determine and deliver pressure during nasal CPAP therapy for obstructive sleep apnoea. Thorax 2006;61:226-31.

30. Patil SP, Ayappa IA, Caples SM, Kimoff RJ, Patel SR, Harrod CG. Treatment of adult obstructive sleep apnea with positive airway pressure: an American academy of sleep medicine systematic review, meta-analysis, and GRADE assessment. J Clin Sleep Med 2019;15:301-34. 